it also occurred occasionally as a complication of, among other conditions, deep infection and intracranial haemorrhage. The term "cold syndrome" is preferable to " co!d injury."

A wide variety of clinical conditions was encountered. Numerous basically different clinical and pathological conditions gave rise to closely similar initial signs; and of conditions giving rise to any particular early clinical sign some were associated with a grave prognosis and others with only temporarily disturbed progress.

The challenge to the family doctor was to arrive at a rapid appraisal of an infant's general state, and decision to transfer to hospital was often made within an hour of birth. Few, if any, of the deaths were avoidable. Life-saving factors included the awareness of the domiciliary midwife of the need to anticipate, the consistently sound clinical judgment of the family doctor, the invariably prompt response to requests for transport, and the skilled experience of the hospital midwife in specialized nursing care of the ill newly born baby. It is debatable whether an emergency resuscitative team is needed in all areas.

Whatever results may follow official encouragement of hospital confinements a need will remain for special hospital provision for ill, and small premature, babies newly born on district. Where provision is made in a general hospital, the special unit for the care of the newly born baby should be incorporated in the maternity and not in the children's unit, and provision should include surgical, radiological, laboratory, and post-mortem services, with experience of the special requirements of the newborn. It is in the interests of administrative and clinical efficiency that any special baby-care unit for newborn infants should serve a defined domiciliary district or districts.

\section{REFERENCES}

Ministry of Health (1961). Prevention of Prematurity and the Care of Premature Infants. H.M.S.O., London.

(1962). A Hospital Plan for England and Wales, Cmnd. 1604. H.M.S.O., London.

\title{
LATE RESULTS OF ARTERIAL RECONSTRUCTIVE SURGERY
}

\section{BY \\ H. S. SHUCKSMITH, T.D., M.B., B.Sc., F.R.C.S. $\quad$ N. V. ADDISON, M.B., F.R.C.S.}

\section{General Infirmary at Leeds}

Peripheral arterial occlusions and aneurysms dus to atherosclerosis have bean treated by reconstructive surgery in 230 patients between 1954 and 1961 . Methods employed for arterial blocks have been either reconstitution of the arterial lumen by thrcmboendarterectomy or the by-pass graft, and in aneurysms by excision with graft replacement. The purpose of this paper is to review the long-term results from reconstructive surgery, based on the first 200 patients (Table I), who were followed up for at least one year after operation, some as long as seven years. Results

TABle I.-Type of Arterial Reconstruction Carried Out in First 200 Cases

Type of Reconstruction

\begin{tabular}{lllll} 
Type of Reconstruction & & & \multicolumn{2}{c}{ No. of } \\
Aorto-iliac thromboendarterectomy & $\ldots$ & $\ldots$ & $\ldots$ & 24 \\
and femoral by-pass grafts & $\cdots$ & $\ldots$ &.. & 25
\end{tabular}

Resection of aortic aneurysm, replacement with graft: Abdominal Thoracic

Femoro-popliteai thromboendarterectomy

" by-pass grafis

Common and internal carotid thromboendarterectomy ..

Subclavian thromboendarterectomy

Resection of popliteal aneurysm, replacement with graft ..

o. of Cases

28

28
1
38

76

6

were judged successful if the peripheral pulses (femoral and posterior tibial) were restored (Table II) and the symptoms relieved; otherwise they have been classified as failures.

It is a small series and therefore detailed statistical analysis is out of place, but the results are comparable with those published by Cockett and Norman (1958) and Tibbs (1960), and are even in line with the large series reported by Crawford et al. (1960) and Roo and Downs (1960).

The late results of these reconstructive operations are shown in Table II. It is evident that the benefits from surgery in aorto-iliac disease are substantial and better than the long-term results obtained in blocks in the femoro-popliteal arteries.

Errors in surgical technique have accounted for several of the failures, partly because this work has bzen carried out as a side-line of general surgery and operations have not been repeated often enough to become technically perfect. Even when the operative technique has been adequate some immediately good results have been short-lived because atherosclerosis is nearly always a generalized disease and further thrombosis is likely to occur. Our experience is very similar to that of Pratt (1960b), who records that he does not see enough patients in whom the atherosclerosis is sufficiently localized to produce good and lasting results after surgery.

Direct reconstructive surgery can be of much benefit to a patient, but there are many pitfalls in its application, particularly when an abdominal operation is involved; the long-term results in the smaller arteries are disappointing. The results shown in this series make a conservative attitude in selection desirable, and reconstructive surgery (except in expert hands) ought to be

\begin{tabular}{|c|c|c|c|c|c|c|c|c|}
\hline & \multicolumn{2}{|c|}{$\begin{array}{c}\text { Anrtic } \\
\text { Aneurysms }\end{array}$} & \multicolumn{3}{|c|}{$\begin{array}{l}\text { Aortn-iliac and } \\
\text { External Iliac }\end{array}$} & \multicolumn{3}{|c|}{$\begin{array}{l}\text { Femnro- } \\
\text { popliteal }\end{array}$} \\
\hline & 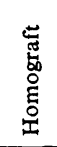 & 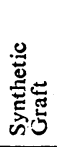 & 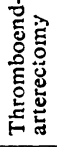 & 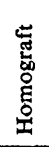 & 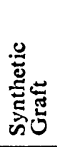 & 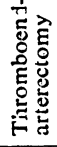 & 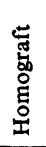 & 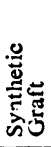 \\
\hline $\begin{array}{l}\text { No. of cases } \\
\text { Early failures } \\
\text { Pateent vessels on }\end{array}$ & $\begin{array}{r}1.4 \\
4\end{array}$ & $\begin{array}{r}15 \\
6\end{array}$ & $\begin{array}{r}24 \\
3\end{array}$ & $\begin{array}{r}12 \\
1\end{array}$ & $\begin{array}{r}13 \\
2\end{array}$ & $\begin{array}{r}38 \\
2\end{array}$ & $\begin{array}{r}23 \\
3\end{array}$ & $\begin{array}{l}53 \\
13\end{array}$ \\
\hline $\begin{array}{l}\text { hospital irom } \\
\text { Thrombosis of } \\
\text { segment in 1st }\end{array}$ & 10 & 9 & 21 & 11 & 11 & 36 & 20 & 40 \\
\hline $\begin{array}{c}\text { year } \\
\text { Patency at: }\end{array}$ & - & - & 5 & 1 & 1 & 9 & 10 & 12 \\
\hline $\begin{array}{ll}\text { 1st year } & . \\
\text { 2nd }, & \end{array}$ & $\overline{1}$ & $\begin{array}{l}4 \\
2\end{array}$ & $\begin{array}{l}5 \\
8\end{array}$ & $\overline{2}$ & $\begin{array}{l}3 \\
2\end{array}$ & $\begin{array}{r}13 \\
8\end{array}$ & $\begin{array}{l}\mathbf{0} \\
7\end{array}$ & $\begin{array}{r}18 \\
8\end{array}$ \\
\hline 3 rd $"$ & 3 & 3 & 3 & 3 & 4 & 6 & 2 & $\begin{array}{l}0 \\
2 \\
\end{array}$ \\
\hline 5th ", & $\frac{2}{2}$ & 二 & $\overline{-}$ & 1 & -1 & 二 & - & $\bar{z}$ \\
\hline $\begin{array}{ll}\text { 6th } & \text { 6th }\end{array}$ & $\sqrt{2}$ & $=$ & $\bar{z}$ & 1 & $=$ & $\bar{z}$ & $\bar{z}$ & $=$ \\
\hline $\begin{array}{l}\text { Deaths" in hos- } \\
\text { pital }\end{array}$ & 4 & 6 & 1 & 1 & $\mathbf{0}$ & 1 & - & $t$ \\
\hline $\begin{array}{l}\text { Late deaths up to } \\
3 \text { years }\end{array}$ & 3 & 3 & 3 & 2 & 2 & & 4 & 4 \\
\hline Amputations.. & & 1 & 3 & $i$ & $\overline{2}$ & 6 & 4 & 18 \\
\hline
\end{tabular}


undertaken only when the atherosclerosis is causing severe disablement or there is a danger to life or limb. Reconstructive surgery is often best avoided when a patient can live pleasantly with his dicablement, because disease of the coronary or cerebral arteries is more likely to prove fatal (Bloor, 1961).

\section{Arteriography}

It is perhaps at first sight strange that arteriography (which inade possible the study of local blozks in the arteries of living subjects and so led to reconstructive arterial surgery) is used less and less in the investigation before treatment. It is a procedure fraugint with dangers, it requires great skill in its performance, and its interpretation relies on a knowledge of the pathology of the living as seen at operation.

The risk of proteinuria from the medium injected has to be accepted (Kirkland and Haslock, 1961). Translumbar aortography can demonstrate the corta and its divisions adequately and safely only if the needle pierces the aorta at the level of the first lumbar vertebra, and even then a haematoma may be produced. Such a haematoma which became infected caused the death of one of our patients in this series. Aortography by the Seldinger (1953) method of introducing a cannula and then a catheter into the pulsating femoral artery is an easier technique, but, even so, penetration of the iliac artery and dislodgment of clot to cause gangrene of the limb has been seen; this method, employed to demonstrate the state of the popliteal artery, has rot been impressive. The most consistently useful arteriogram in this series is one carried out by the surgson when operating for a femoro-popliteal block. After the common femoral artery has been exposed $20 \mathrm{ml}$. of $70 \%$ "urographin" is injected and an excellent picture of the femoral and popliteal arteries on a single film is obtained.

When the foot is ischaemic and the common femoral pulses are impalpable the pathology is such that the deep femoral artery (except at its ostium), the distal popliteal, and at least one of three arteries in the calf are likely to be patent, and this makes it possible to proceed to a successful operation without arteriography.

Aortography is of no help in the surgery of distal aortic or popliteal aneurysms, but is an aid in other conditions. If the operator can pierce the aorta at the level of the first lumbar vertebra consistently, then the demonstration of patent distal arteries makes their exposure as a first step in any aorto-iliac operation unneccessary.

\section{Aorto-iliac Blocks}

Thromboendarterectomy was introduced by Cid Dos Santos (1947) and grafting for the blocked aortic bifurcation by Oudot (1951a, 1951b).

\section{Resuits and Follow-up (Grafts)}

In this series grafts have been used in 25 patients since 1954. Twelve homografts and 12 nylon or "tefion" prostheses were used with equal success. One polyvinylresin graft was used, but was unsatisfactory. There were three early failures, with one death shortly after operation, caused by thrombosis of the aorta extending proximal to the renal arteries.

Peripheral pulses were restored to the femoral artery in $22(88 \%)$ patients, and in the posterior tibial in 18 (72\%). Among 22 patients who left hospital with restored peripheral pulses there were two failures in the first year, when the grafts ceased to be patent.

The remaining 20 patients were followed up at regular intervals, and when the posterior tibial pulse was restored the grafts remained patent for a minimum of one year to a maximum of seven years (Table II) in $18(72 \%)$ patients. In one woman a homograft has remained patent for seven years, but she has recently developed intermittent claudication in both calies. There were four deaths in the follow-up period within three years of operation. Three patients died from coronary thrombosis, but the grafts were patent when they were last sean. The fourth patient died as a result of sepsis, which persisted after removal of the graft, whereas sepsis settled in two other patients (in the early post-operative period) after removal of the synthetic grafts.

\section{Resu'ts and Follow-up (Thromboendarterectomy)}

Thromboendarterestomy has been carried out in 24 patients since 1958. There were three early failures with one death caused by heparin given immediately after oparation.

The femoral pulses were restored in $21(87 \%)$ patients and the posterior tibial in $16(66 \%)$. Among 21 patients who left hosp:tal with restored peripheral pulses there were five failures in the first year. One of these patients died six months after operation following partial gastrectomy for haematemesis produced by a fistula between the right common iliac artery at the line of suture and the third part of the duodenum (Shucksmith and Wilson, 1961).

The remaining 16 patients were followed up. When the posterior tibial pulse was restored it remained palpable from a minimum of one year to a maximum of three and a half years in these $16(66 \%)$ patients. There were three deaths in the follow-up period within three years of operation. Two patients died from coronary thrombosis, both having palpable peripheral pulses when last seen before death. The cause of death in the third patient was unknown.

\section{Functional Resu'ts from Grafts or Thromboendarterectomy}

The excellent functional results following the use of grafts or thromboendarterectomy show that $70 \%$ of patients are fit and well and that either procedure can abolish intermittent claudication for years, provided a lumen exists in the superficial femoral, popliteal, and calf arteries; operation is advised if claudication is caused by an aorto-iliac block. If the femoro-popliteal or calf arteries are blocked in addition to the il ac arteries, then it is unlikely that aorto-iliac procedures alone will relieve claudication. In such patients the deep femoral artery is nearly always patent, even though the iliac and femoro-popliteal arteries are blocked, and bringing more blood to the common femoral (and so to the deep femoral artery) may well relieve rest pain but will not alleviate claudication. Occasionally, grafts from the aorta to popliteal arteries will be useful for claudication; thromboendarterectomy of all these arteries together is possible, but the undertaking is formidable. Such interventions are worth while when there is pain in the foot at rest or ischaemic lesions are developing in the foot or toes and the common femoral pulse is impalpab!e. If the common femoral pulse is absent at the beginning of the operation but a lumen and back-bleeding from the deep or superficial femoral 
arteries can be established by thromboendarterectomy, it is justifiaile to expose the aorta and proceed.

In most of the patients in whom a graft has been used the abdominal aorta was divided about $8 \mathrm{~cm}$. below the level of the renal arteries, proximal thromboendarterectomy effected, and the graft sutured to the endarterectomized aorta. The distal limbs of the graft have been anastomosed either to the common iliac or, more often, to the common femoral arteries, but on two occasions one limb of the graft was anastomosed to the popliteal artery. One of the difficulties in grafting is to make certain that all thrombus has been removed before the circulation is re-established. Some hours may elapse before distal pulses are palpable, which seems to indicate that soft thrombus is often left at the operation site.

Thromboendarterectomy of the aorta and iliac arteries demands an even more careful dissection than for the insertion of a graft, because all the branches of the aorta between the renal and iliac arteries must be identified and clamped; thromboendarterectomy can be accomplished only in a bloodless field. Thromboendarterectomy is effected by using linear arteriotomy wounds to introduce strippers, and we have found that by using Martin's (1961a) strippers extensive incisions into the aorta and iliac arteries are not necessary. The atheromatous material which is removed in thromboendarterectomy is always maximal on the posterior wall of the aorta and common iliac arteries, and it is commonly calcified. Large plaques of calcified atheroma are frequently removed, leaving a thin artery wall, which fortunately is nearly always adequate to function as a conduit. Sometimes a gap is left after a large plaque has been removed, and this may mean abandoning the thromboendarterectomy and using a graft. It is always wise to have a graft available when thromboendarterectomy is being attempted.

\section{Aortic Aneurysms}

Resection of an aortic aneurysm and homograft replacement was first accomplished by Dubost et al. (1951).

\section{Results and Follow-up}

Twenty-nine patients suffering from aortic aneurysms underwent resection of the aneurysm and graft replacement. Fourteen homografts, the first three stored in Gross's solution (Gross et al., 1949) and the remainder prepared by the single-stage freeze-drying process, and 15 synthetic grafts (Edward Tapp's woven nylon or knitted teflon or "dacron") were used.

There were 10 deaths in hospital and the operative mortality was $34 \%$, but three of these patients underwent operation because of an acute rupture of the aneurysm and died within nine days. Elective surgery was carried out on 26 patients, and the mortality for this group was $24 \%$, there being seven deaths within one month of operation. One patient died during operation because the aorta was so calcified that the occluding clamp cut through the aorta. A second patient lost so much blood from damage to the inferior vena cava that rapid transfusion did not prevent subsequent cerebral complications. A poor distal anastomosis or blockage by soft clot was the cause of unilateral anterior tibial necrosis in three patients, and the resulting gangrene caused the death of one of them. Intestinal ileus was responsible for two deaths. A tetraplegia caused the death of one patient after resection of an aneurysm of the lower thoracic aorta, and another patient died after developing a suppurative bronchopneumonia.

The remaining $19(65 \%)$ patients were followed up at regular intervals and were found to have remained well and symptom-free from a minimum of one year to a maximum of seven years after operation (Table II). There were six deaths in the follow-up period within three years of operation. Rupture near the proximal suture line of the aortic graft was responsible for three deaths, presenting in one patient as haematemesis from rupture into the duodenum (Shucksmith and Wilson, 1961). Two patients died from coronary thrombosis and one from cerebral haemorrhage.

Patients of any age have been selected for operation when the aneurysm has produced symptoms. More than $50 \%$ of the patients have lived normal lives for many years after the operation, and our first patient, aged 27 when operation was undertaken in 1954, is well, and so is our oldest patient, aged 73 when the aneurysm was resected in 1957.

Surgery of the distal aortic abdominal aneurysm is facilitated by the fact that loss of elastic tissue in the wall of the aorta produces elongation as well as dilatation of that artery. This elongation provides a sufficient length of the aorta between the renal arteries and the aneurysm for the occluding clamp to be applied distal to the renal arteries. The common iliac arteries are nearly always dilated or aneurysmal, but in most patients they can be used at some level for the distal anastomosis of the graft. Only occasionally is the external iliac artery blocked, and then the distal anastomosis is made to the common femoral artery. Bilateral anastomoses to the common femoral arteries are to be avoided if possible, because gangrene of the pelvic viscera may ensue. In the early operations most of the aneurysm was excised, sometimes leading to damage to the inferior vena cava or common iliac veins. In the later operations the dissection has been limited to isolating the aorta distal to the renal arteries, dissecting out the common iliac arteries, and then, after application of the clamps, excising the anterior wall of the aorta, evacuating clot, and underrunning any lumbar arteries which bleed. Martin's (1961b) method of merely opening the aneurysm is useful, since it gives added protection to the great veins.

\section{Femoro-popliteal Blocks}

The use of autogenous vein grafts as a by-pass from the femoral to the popliteal artery was introduced by Kunlin (1949), and the closed method of femoropopliteal thromboendarterectomy was described by Cannon and Barker (1955) and by Cannon et al. (1958).

\section{Results and Follow-up (Grafts)}

In this series 114 patients with femoro-popliteal blocks have been treated since 1955, using by-pass grafts in 76 patients. Twenty-three homografts, 48 teflon or dacron grafts, and 5 polyvinyl-resin grafts have been used. There were 16 early failures, with one death from coronary thrombosis six hours after operation.

The posterior tibial pulse was restored in $60(78 \%)$ patients. During the first year there were 22 failures judged by the return of ischaemic pain and the disappearance of the posterior tibial pulse. The remaining 38 patients were followed up. When the 
posterior tibial pulse was palpable the grafts remained patent for a minimum of one year to a maximum of four years after operation in these $38(50 \%)$ patients. During the follow-up period eight patients died within three years of operation, mostly from coronary thrombosis, but in all these eight the posterior tibial pulse was palpable when last seen before death.

The long-term results with all types of grafts used in the leg have been disappointing, and only 5 out of 76 by-pass grafts have maintained their patency for three or more years. Major amputations were eventually carried out in 22 patients between one and four years after the insertion of a by-pass graft.

\section{Results and Follow-up (Thromboendarterectomy)}

Thromboendarterectomy was carried out in 38 patients, and there were two early failures, with one death from haematemesis, three weeks after operation.

The posterior tibial pulse was restored in $36(94 \%)$ patients, but during the first year there were nine failures due to further thrombosis in the femoropopliteal arteries. The remaining 27 patients were followed up. When the posterior tibial pulse was restored it remained palpable from a minimum of one year to a maximum of three years after operation in these $27(71 \%)$ patients. No deaths were recorded in the follow-up period.

Whenever the posterior tibial pulse was restored after either thromboendarterectomy or the use of the by-pass graft, clinical improvement was dramatic. Even though the posterior tibial pulse was not restored in 14 out of 57 patients by such procedures ;erformed for rest-pain or gangrene, there was some clinical improvement, and hardly ever was the condition made worse. Major amputation was prevented or delayed in 27 patients, and, except in those in whom a haematoma developed, the procedures, even if unsuccessful in restoring peripheral pulses, did not precipitate amputation. The main complication of these procedures has been a wound haematoma in seven patients, four of which became septic. A graft had been used in three of these four patients, and they all required above-knee amputation, but in the patient subjected to thromboendarterectomy amputation was not necessary.

Patients were selected for either of these procedures because of rest-pain in the foot, dry peripheral gangrenous lesions, or intermittent claudication severe enough to prevent their working. The decision whether to attempt thromboendarterectomy or use a graft was influenced by the degree of linear calcification shown on a plain radiograph and the limitation of the block demonstrated by an arteriogram made after the common femoral artery was exposed. If reconstructive surgery is possible then the popliteal artery is exposed through an incision on the inner side of the knee (the long saphenous nerve being avoided) between sartorius and the adductor magnus tendon or dividing all tendons and muscles attached to the inner condyle or upper part of the shaft of the tibia for the distal part of the popliteal artery.

When femoro-popliteal blocks are not calcified, the arteriogram shows good filling of the distal popliteal artery, and an arteriotomy of this artery allows good back-bleeding, thromboendarterectomy is attempted. A by-pass graft is used if thromboendarterectomy fails or if there is much calcification or the block in the popliteal artery extends down to the level of the knee- joint. If the distal popliteal artery is blocked a lumbar sympathectomy is employed. for it occasionally relieves rest-pain and always produces a warm, better-nourished skin. Thromboendarterectomy is carried out by introducing Martin's strippers or Cannon's loop-knife through arteriotomy wounds in the common femoral and popliteal arteries. These instruments pass most easily along the artery when the atheroma is thick and cheesy in consistency. If the atheroma is thin or if it extends irregularly into the media (which is likely if the plain radiograph shows calcification) it is difficult to find a plane of cleavage and the loop-knife may be pushed through the artery wall. The most difficult part of thromboendarterectomy is to leave the intima with a smooth edge firmly attached all round the circumference of the distal artery.

The by-pass graft is tunnelled subcutaneously through an oesophagoscope from the common femoral artery to the popliteal fossa, the distal end-to-side anastomosis is done first (because it can be performed more easily when the graft is slack), and then, with the graft pulled taut, it is anastomosed to the common femoral artery. The anastomosis to the popliteal artery is difficult to accomplish without constriction of the lumen at the distal lip. This difficulty is greater when the anastomosis is made to the popliteal artery behind the tibia, because the artery is narrower at this level than it is behind the femur.

\section{Discussion Grafts}

Polyvinyl-resin grafts have been the only unsatisfactory grafts used in reconstructive procedures. The homograft prepared in Gross's solution or by the singlestage freeze-dried process has the advantage that no blood was lost when blood flow was initiated and a new intima is formed after some weeks (Shucksmith et al., 1958). It is reported that the homograft stored in formalin is equally satisfactory (Nuboer, 1954).

The knitted teflon or dacron graft has replaced the homograft because in grafting for aortic aneurysms it has the advantage that it is wider than the homograft and can therefore be stitched more easily to the wide aortic and iliac arteries found in this condition. A possible defect with the synthetic graft is that no new intima is formed (Warren et al., 1961), since it is lined merely by a layer of soft yellow fibrin; but, even so, these grafts remain patent when anastomosed to the large arteries. Knitted crimped teflon or dacron grafts 6 to $8 \mathrm{~mm}$. in diameter have been used in the femoropopliteal by-pass procedures, but patency after two years has been exceptional. The nature of the graft may be the cause of the unsatisfactory results, because no new intima forms in it. Linton's (1959) results using autogenous saphenous vein by-pass grafts are much better than those reported by others (Pratt, 1960a ; Tibbs, 1960) using synthetic material for the by-pass grafts. It is very possible, however, that the relatively poor results of the femoro-popliteal by-pass operation are due to defects at the anastomosis which lead to early thrombosis at or near this site.

In material examined when a graft has blocked it is most often found that the block started at or just distal to the popliteal anastomosis. Such an early block is to be expected if the artery is narrowed when suturing the graft in place, because this constriction, together with the turbulence of the blood-stream caused by the altered direction of the oblique end-to-side anastomosis 
(Phelan and Herrick, 1958), is likely to produce a deposit of fibrin on the artery wall, which at the time of the anastomosis was already atheromatous. The best result in this area in this series is an end-to-end replacement of a popliteal aneurysm with a homograft nearly five years ago. Linton's method of anastomosis and his use of the saphenous vein for the by-pass gives excellent results, but Hiertonn's (1960) series of vein replacement and end-to-end anastomoses is likewise outstanding. It would seem that either of these practices has much to commend it.

\section{Thromboendarterectomy}

Thromboendarterectomy by the semi-open method (a procedure much facilitated in the aorto-iliac arteries by the use of Martin's strippers) is more time-consuming than the use of grafts in the aorto-iliac region, but there have been fewer post-operative complications. If sepsis develops there is no graft to remove, a new intima forms (Barker et al.; 1955 ; Shucksmith and Wilson, 1959), and there is less risk of late leakage at the suture lines. Thromboendarterectomy, which is theoretically much better than a graft in the femoro-popliteal region because axial flow is restored, ean be difficult to perform using the relatively closed method with Cannon's loop-knives. Infrequently, it is not easy to clear the block in the region near the adductor magnus tendon, but when atheroma is cheesy, then 20 to $25 \mathrm{~cm}$. of block may be removed. There is less danger from soft clot giving distal obstruction in thromboendarterectomy than in by-pass grafts.

\section{Anticoagulants}

Heparin (40 mg.) was given intravenously before the arterial clamps were applied, and if the clamps had been in place for less than one hour then $40 \mathrm{mg}$. of protamine sulphate was administered after their release. The practice of giving heparin after operation (Cannon and Barker, 1955) was found to cause so much bleeding that we have not used it post-operatively.

Phenindione ("dindevan") has been given from the fourth post-operative day in sufficient dosage to ensure that the prothrombin time, as estimated by Quick's method, is approximately twice that of the control. Although this dosage has been maintained, venous thrombosis has been common ; pulmonary embolus has not been prevented; epistaxis, cerebral haemorrhage, haematuria with clot retention, bruising, skin rashes, and pruritus have been seen ; and further arterial thrombosis has not been prevented. Phenindione is not now used post-operatively.

\section{Selection of Cases for Operation}

Table II records many successes in the treatment of patients who had aneurysms, intermittent claudication, pain at rest in the foot, or impending gangrene. There was a high mortality in the aneurysm group: the best functional results were in the treatment of aorto-iliac blocks, but the results of treating blocks below the groin were disappointing. Better results can be obtained, for deaths and morbidity have been caused by faults in technique. Better popliteal anastomoses, using by-pass veın grafts or end-to-end vein grafts after excision of femoro-popliteal blocks, may much improve the results in this region. Even so, it is well to remember that atherosclerosis usually involves many arteries other than the one causing symptoms and that the disease continues to progress in areas other than the one treated by operation. Reconstructive surgery ought to be confined to patients who have symptoms as well as signs and in whom claudication is disabling if it is the only evidence of atherosclerosis. Operation is confidently advised to the patient having an abdominal aortic aneurysm which is causing pain or genito-urinary symptoms, to the patient whose claudication is caused by an aortic or iliac artery block, to the patient with ischaemic neuritis of the foot whose proximal block may be femoro-popliteal, iliac, or both, and to the patient having impending dry gangrene of the toes. Operation is undertaken for claudication caused by a femoro-popliteal block when the patient has been told the result may be short-lived. These results do not justify a wide range of indications for operation; better results may do so.

\section{Summary}

The late results of arterial reconstructive surgery in the first 200 of the 230 patients operated upon between 1954 and 1961 are presented.

Patients were followed up at regular intervals for at least one year after operation, some for as long as seven years.

Twenty-eight aneurysms of the distal abdominal aorta have been treated by resection and use of grafts. Blocks of the aortic bifurcation and common iliac arteries have been treated either by open thromboendarterectomy (24) or with by-pass grafts (25), and blocks in the femoropopliteal arteries by either closed thromboendarterectomy (38) or with by-pass grafts (76).

The best functional results are in the treatment of aorto-iliac blocks following either the use of grafts or thromboendarterectomy, and $70 \%$ of patients are fit and well. When the posterior tibial pulse was restored the long-term results have been excellent.

The late results in femoro-popliteal blocks using by-pass grafts are disappointing, and only 5 out of 76 grafts have maintained their patency for three or more years. The results from femoro-popliteal thromboendarterectomy are more encouraging.

Thromboendarterectomy is preferred to the use of by-pass grafts because normal axial blood flow is maintained and a new intima forms.

Reasons for the relatively short-lived benefits from operations on the smaller arteries below the inguinal ligament are discussed.

Although there is a high mortality in the abdominal aortic aneurysm group, $65 \%$ of the patients have lived normal lives for several years after operation. Synthetic grafts are preferred to homografts because they are wider and function well.

Avoidable errors in technique which have accounted for some of the poor results are described.

Overall results better than those described in this series may justify operation for patients less incapacitated than those selected here, but, even so, the generalized nature of atherosclerosis must always be remembered before advising operation.

\section{REFERENCES}

Barker, W. F., Cannon, J. A., Zeldis, L. J., and Ah'tye, P. (1955). Surg. Forum. 6, i66.

Bloor, K. (19n1). Ann. roy. Coll. Surg. Engl., 28. 36 Cannon, J. A., and Barker, W. F. (1955). Surgery, 38, 48 Cond $K_{1}$ wakami. 1. G. (1958). ibid.. 43. 76. Cockett. F. B., and Norman, A. G. (1958). Brit. med. J., 1, 727 Crawford, E. S., De Bakey, M. E., Morris, G. C., and Garrett, E. (1960). Surgery, 47, 79. 
Dos Santos. J C. (1947). Mém. Acad. Chir., 73, 409.

Dubost, C., Allary, M., and Oeconomos, N. (1951). Ibid., 77, 381.

Gross, $\dot{R}$. E.. Bill, A. H., and Peirce, E. C. (1949). Surg. Gynec. Obstet., 88. 689.

Hiertonn, T. (1960). Acta chir. scand., 119, 129.

Kirkland, J. A., and Haslock, M. R. (1961). Lancet, 1, 693.

Kunlin, J. (1440). Arch. Mal. Caur., 42, 371.

Linton, R. R. (1959). New Engl. J. Med., 260, 272.

Martin, P. (1961a). Brit. med.J., 1, 1457.

(1961b). Brit. J. Surg., 48, 530.

Nuboer, J. F. (1954) Arch. chir. neerl., 6, 123

Oudot, J. (1951a) Presse méd., 59, 234.

(1951b) Mém. Açad. Chir., 77, 636.

Phelan, J. T., and Herrick, J. F.' (1958). Proc. Mayo Clin., 33, 108.

Pratt, G. H. (1960a). Amer. J. Surg., 100, 389.

- (1960b). Minerva cardioangiol. europ., 6, 5.

Rob, C. G., and Downs, A. R. (1960). J. cardiovasc. Surg. (Torino) 1. 57

Seldinger, S. I. (1953). Acta radiol (Stockh.), 39, 369

Shucksmith, H. S., Mitchell, W. M., and Zinneman, K. (1958). Brit. J. Surg., 46, 141 .

- and Wilson, G. (1959). Lancet, 1, 601.

Tibbs (1961). Brit. med. J." $2,567$.

Warren, R., John, H. T., Shepherd, R. C., and Villavicencio, J. L. (1961). Surgery, 49, 1.

\section{FEMORO-POPLITEAL ARTERIAL} OBSTRUCTIONS

\section{LATE RESULtS OF TEFLON PROSTHESES AND ARTERIAL HOMOGRAFTS}

$\mathbf{B Y}$

F. ASHTON, Ch.M., F.R.C.S.

Lecturer in Surgery, University of Birmingham

G. SLANEY, Ch.M., F.R.C.S.

Senior Lechurer in Surgery, University of Birmingham

AND

A. J. H. RAINS, M.S., F.R.C.S.

Professor of Surgery in the University of London, at Charing Cross Hospital Medical School

The treatment of ischaemic disease of the legs due to thrombo-obliterative disease of the femoral and popliteal arteries by restorative procedures, by-passing or removing the obstruction, has been in use for several years. In this centre this type of disease in suitable cases has been treated by the by-pass operation, and endarterectomy has been but little used until recently.

This paper concerns two periods in the direct surgical treatment of this disease: the first from 1953 until 1959, when freeze-dried homografts were used: the second from early 1960 to date, when woven or knitted crimped "teflon" tubes $5 / 16$ in. $(8 \mathrm{~mm}$.) in diameter were inserted. Forty-six patients had restorative surgery ; three had bilateral procedures, and two had a repeat graft, making a total of 51 by-pass operations. There were two operative deaths, and two patients could not be traced.

\section{Selection of Cases}

We have had no cause to liberalize our criteria for operation in these cases, since they were stated by Ashton and Rains (1960); indeed, we are if anything more conservative. Claudication alone is not considered to be an indication for operation unless it is cripplingthat is, it comes on after walking less than 50 yards (46 metres). A lesser degree of claudication may in rare cases be accepted when it is seriously interfering with the patient's occupation. Rest-pain, ulceration, and impending or frank gangrene were the reasons for operation in $41(89 \%)$ of our cases.

Any success, however limited, in the latter group represented a positive gain, since the alternative was early amputation; and from the point of view of limb survival nothing, therefore, was to be lost by attempts at grafting, whatever the outcome. The age of the patients varied from 31 to 74 years, the greatest number (23) being in the sixth decade.

Duration of Symptoms. - The duration of symptoms varied from six weeks to six years, with an average of two years. Those patients whose symptoms had existed for only a short time usually had gangrene of the extremity. Those whose history was longer had claudication as a principal symptom, surgery being precipitated by the onset of the more clamant symptums of rest-pain, gangrene, or claudication after a few steps.

\section{Concomitant Disease}

Six patients had diabetes-two with coronary-artery disease. One operative death occurred in this group : in the remaining five, two grafts are still open at three years and 18 months after the operation.

Eleven patients had arterial hypertension-that is, a diastolic pressure of over $100 \mathrm{~mm}$. $\mathrm{Hg}$. Three of these grafts are still open. There was one operative death in this group, and one patient has since died.

Electrocardiographic Changes.-Patients with obliterative arterial disease in the legs are likely to have similar generalized disease to a greater or less degree. Though only three patients showed an ischaemic pattern on E.C.G., two of these died as a result of the operation, showing how adversely this factor may affect the prognosis.

\section{Arteriography}

It has been the practice in this unit to perform aortography, preferably by retrograde femoral catheterization, in every case where femoro-popliteal grafting is considered. Besides providing information abour the nature and extent of the blockage in the superficial femoral artery, we feel it is of prime importance to know about the degree of patency of the iliac vessels, which in the event of grafting govern the flow into the graft. It is not always possible to judge the patency of the iliacs by the magnitude of the femoral pulse in a resting limb, and if iliac disease is present it may be necessary to attach the graft to the common iliac artery or aorta above the obstruction.

Radiographic assessment of the patency of the popliteal artery is preferable to direct exploration, a procedure which carries risk to the limb by damaging collateral vessels if grafting is not possible. Furthermore, while the state of the tibial vessels can be roughly ascertained by the amount of back-bleeding on opening the popliteal artery it cannot be accurately known without arteriography with delayed films-retarded sufficiently to allow the vessels in the most ischaemic limb time to fill.

\section{The Operation}

In most cases the upper end of the graft was sewn end-to-side to the common femoral artery. If there was severe disease of this vessel a localized endarterectomy was carried out, and prior to anastomosing the graft an opportunity was taken to clear out the origin of the profunda femoris artery. There is now good experimental and clinical evidence that this latter step may 